\title{
Pulse Oximetry a Non-Invasive Screening Test to Intensify Primary Diagnosis of Critical Cyanotic Congenital Heart Disease in Neonates- A Retrospective Study
}

\author{
Sanjay Kumar Nirala ${ }^{1}$ Kripanath Mishra², Anil Kumar³, Randhir Kumar Mishra ${ }^{4}$
}

\begin{abstract}
${ }^{1}$ Department of Paediatrics, Darbhanga Medical College and Hospital, Darbhanga, Bihar, India. ${ }^{2}$ Department of Paediatrics, Darbhanga Medical College and Hospital, Darbhanga, Bihar, India. ${ }^{3}$ Department of Paediatrics, Darbhanga Medical College and Hospital, Darbhanga, Bihar, India. ${ }^{4}$ Department of Paediatrics, Darbhanga Medical College and Hospital, Darbhanga, Bihar, India.
\end{abstract}

\section{ABSTRACT}

\section{BACKGROUND}

Pulse oximetry is an important screening technique to intensify timely diagnosis of critical cyanotic congenital heart disease in neonates which is a noninvasive, safe and an easy method. It is a highly specific test having low false positive rates. This screening test was conducted in Department of Pediatrics, Darbhanga Medical College \& Hospital, Laheriasarai, Darbhanga, Bihar, between 24 hours and 36 hours after birth, with use of the right hand of infants and either foot to diminish false positive results.

\section{METHODS}

Data for study has been collected from birth records from Darbhanga Medical College \& Hospital, Bihar, and included-1. saturation level from either feet and right hand for the primary and further recurrence of screening. 2. outcomes of the echocardiographic test findings. 3. important non-cardiac illness diagnosed at the hospitalization for infants which failed screening for cyanotic CHD. For the correction of errors related to data of the study, we satisfied autonomous investigations of pulse oximetry requiring AAP CCHD screening algorithm to identify infants to pass with a saturation $\geq 95 \%$ in hand or either foot and a $\leq 3 \%$ difference and those falling after finishing 3 transitional screening tests. After three consecutive measurements, there is difference of $\mathrm{SpO}_{2}$ of more than $3 \%$ between pre-ductal and post-ductal $\mathrm{SpO}_{2}$

\section{RESULTS}

The combination of pulse oximetry and physical examination improved the sensitivity to up to $57.14 \%$ with a specificity of $99.73 \%$. The overall mortality rate of CCHD was $36.8 \%$ [ 7 out of 19 ]. The mortality rate of early detection were $37.5 \%$ [ 6 out of 16]. Late detection of CCHD has mortality rate of 33.3\% [1 out of 3]. 123 [13.1\%] and 70 [7.4\%] newborns have either foot or right hand $\mathrm{SpO}_{2}$ level $<95 \%$ among 941 study newborns at the time of the initial screening. The mean $\mathrm{SpO}_{2}$ level of either feet and right arm of study newborns were 95.8\% [SD 2.3] and 96.0\% [SD $2.2]$ respectively. Either feet and right arm level of $\mathrm{SpO}_{2}<95 \%$ and either feet to right arm level of $\mathrm{SpO}_{2}$ difference of $>3 \%$ among 142 [15.1\%] study newborns.

\section{CONCLUSIONS}

Pulse oximetry screening for primary diagnosis of critical cyanotic CHD is an easy, economical and non-invasive test which covers the essential criteria in addition to worldwide newborn screening panel. Extensive approval and implementation can considerably reduce the morbidity in newborns infants and is likely to be an additional important tool in low resource settings where most of newborn infants are born without prenatal diagnosis. Although, this study showed reduced sensitivity of pulse oximetry for critical cyanotic CHD nearly $<50 \%$.

\section{KEY WORDS}

Critical Cyanotic Congenital Heart Disease/Critical CCHD, Pulse Oximetry Screening [POS], Newborns

\author{
Corresponding Author: \\ Kripanath Mishra, \\ Department of Paediatrics, \\ Darbhanga Medical College and Hospital, \\ Laheriasarai, Darbhanga-846003, \\ Bihar, India. \\ E-mail:dr.skn07@gmail.com
}

DOI: $10.14260 /$ jemds/2020/233

Financial or Other Competing Interests: None.

How to Cite This Article:

Nirala SK, Mishra K, Kumar A, et al. Pulse oximetry a non-invasive screening test to intensify primary diagnosis of critical cyanotic congenital heart disease in neonates- a retrospective study. J. Evolution Med. Dent. Sci. 2020;9(13): 1082-1086, DOI:

10.14260/jemds/2020/233

Submission 30-11-2019,

Peer Review 07-03-2020

Acceptance 13-03-2020,

Published 30-03-2020.

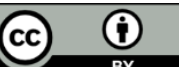




\section{BACKGROUND}

Pulse oximetry is an important screening technique to increase early detection of critical cyanotic congenital heart diseases in neonates which is a noninvasive, safe and easy method. It is highly specific test having low false positive rates. This Screening test conducted in Department of Pediatrics, Darbhanga Medical College \& Hospital, Laheriasarai, Darbhanga, Bihar, have been performed between 24 hours and 36 hours after birth, using the infant's either foot and right hand to reduce false positive results.

Critical cyanotic congenital heart disease is known as condition of the heart disease requiring cardiac surgery or catheter based intervention in the $1^{\text {st }}$ year of life, which occurs in about $25 \%$ of infants with CHD. In infants with critical CHD there is high risk of morbidity and mortality when delay in diagnosis and early referral to a tertiary Centre having experience in managing critical CHD.

A screening test is reflected as positive or negative if oxygen saturations is lower than $95 \%$ in either extremities after three or more consecutive measurements [conducted one hour apart] or if differences of oxygen saturations between pre-ductal and post-ductal is more than $3 \%$ or if there is difference of 3 measurements. Infants who were not undergone primary screening test should have diagnostic echocardiogram and assessment by a physician or cardiologists. ${ }^{1}$ Infants with positive screening test will not always have critical CCHD. Infants with additional illness associated with low $\mathrm{SpO}_{2}$ like persistent pulmonary hypertension and certain haemoglobinopathy may similarly have a positive screening in addition to critical congenital CHD. ${ }^{1}$

The screening test is reflected as positive or negative if quantity of oxygen saturations is lower than $90 \%$, under than $95 \%$ in both extremities after three measurements [one hour apart] or if oxygen saturations more than $3 \%$ between preductal and post-ductal or if there is a difference of 3 measurements.

\section{METHODS}

In Special Newborn Care Unit [SNCU] of Department of Pediatrics, Darbhanga Medical College \& Hospital, Laheriasarai, Darbhanga, Bihar, a retrospective study has been done by Dr. Sanjay Kumar Nirala on newborn Screening for cyanotic CHD by pulse oximetry starting from June 2017 TO DEC 2019. This study has been submitted to this institution and also approved by the same institution. Here, informed consent has not been required as this is the retrospective type of study.

Data for study has been collected from birth records from Darbhanga medical college \& hospital, Laheriasarai, Darbhanga, Bihar, which requires inclusion criteria and exclusion criteria. For the correction of errors related to data of the study, we satisfied an autonomous investigation of pulse oximetry results requiring AAP Critical cyanotic CHD screening algorithm to identify infants as passing with an oxygen saturation $\geq 95 \%$ in hand or either foot and a $\leq 3 \%$ difference and similarly decreasing after completing 3 provisional screening.
Although, the another algorithm currently used Tennessee, primary screening test with either foot and hand with oxygen saturations $\geq 97 \%$ follow on a documentation differing marginally from AAP algorithm. ${ }^{2}$

For early detection of cyanotic CHD, screening for critical Cyanotic CHD with pulse oximetry were included in US Recommended Uniform Screening Panels in 2011 and were recommended by multiple professional societies including American academics of pediatrics (AAP), the American heart association and American College of cardiology to advance primary identification of infants with critical CCHD. ${ }^{3}$

Now, CCHD screening test were proved to decline infant mortality from critical CCHD in regions where screening guidelines are necessary. ${ }^{4}$ CCHD Pulse oximetry screening test were included to the Georgia newborn screening panel in 2015. ${ }^{5}$ Even though, several hospitals in Georgia started using pulse oximetry screening test as soon as $2012 .{ }^{6}$

For late detection of Cyanotic CHD, our work were extended for additional 6 months for follow up for those with negative pulse oximetry result after discharging home where as other studies had offered the follow up for $<6$ weeks after discharging the home. ${ }^{7}$

Everyday nearly 20-30 newborns are delivered in Obs \& Gynae department, Darbhanga medical college and hospital, Laheriasarai, Darbhanga, Bihar. Datas were collected from June 2017 to Dec. 2019. Total 941 term study newborns were incorporated in the study. Asymptomatic newborns at the time of discharged from nursery unit were included in the study. Screening test by $\mathrm{SpO}_{2}$ measurement were done 24 hours after the delivery or before discharge from the hospital. Pulse oximetry probe were sterilized with isopropyl alcohol swab before each examination to inhibit cross-infections. Probe were positioned on either foot and on right hand for 30 seconds and interpretations were verified when an upright and steady waveform witnessed. The next $2^{\text {nd }}$ and $3^{\text {rd }}$ measurements of $\mathrm{SpO}_{2}$ were accomplished after 1 hour for those newborns having positive primary screening test. Partial pressure of oxygen saturation $\geq 95 \%$ in hand or either foot and $\mathrm{a} \leq 3 \%$ difference and those falling after completing 3 provisional screening. Echocardiographic examination that were essential for confirmation of critical CCHD requires$\mathrm{SpO}_{2}$ level $<90 \%$ in any extremity or persistent $\mathrm{SpO}_{2}$ level 90 $94 \%$ in either pre-ductal [right arm] and post-ductal [lower extremity] sites on 3 respective measurements or a insistent pre-ductal to post-ductal $\mathrm{SpO}_{2}$ difference of $>3 \%$.

\section{Inclusion Criteria}

1. Vitals signs should be normal [respiratory rate $30-60$ breaths/min, pulse rate $100-160$ beats/min, temp 36.5 $\left.37.5^{\circ} \mathrm{C}\right]$

2. Clinical features of respiratory distress should be absent.

3. Newborns should take breast feeding and active.

4. Cardiac murmurs should be absent and no feeble pulses.

\section{Exclusion Criteria}

Sick newborns are excluded from the study. Babies having day of life more than 30 days are also excluded. 


\section{Statistical Analysis}

Statistical Package for social Sciences (SPSS) version 20.0 software were applied to analyze the statistical data. The Statistical data had described as mean \pm SD or median along with interquartile range (IQR) for continuous variables and frequencies for categorical variables. Ethical clearance were approved by ethical committee of Darbhanga Medical College \& Hospital, Laheriasarai, Darbhanga, Bihar. Also, informed consent were obtained from parents of each child.

\section{RESULTS}

Total 941 term study newborns were incorporated in the study. The average age of gestation and birth weight of study newborns were taken as 39.4 weeks [SD 1.6] and 3.0768 gram [SD 490.5] respectively. Out of $75 \%$ of the screened newborn [74.2\%] were borne at gestational age between $37-$ 40 weeks and the rest were born between 41-44 weeks. Weights at birth of study newborns ranges from 1400 to $4600 \mathrm{gm}$. Delivery modes were LSCS for 484 [51.4\%] of the study newborns. The essential screening age were considered fewer than 24 hours for 633 [67.3\%] newborns with average age being 8 hours [IQR 6, 24]. Continuously, second and next $\mathrm{SpO}_{2}$ measurement were completed for 142 study newborns and 56 [39.4\%] of them having positive screening test. The echocardiographic examinations were done for total 56 newborns having $\mathrm{SpO}_{2}$ screening test positive. The very sensitive echocardiographic test results were 2 [3.6\%] ASD, 10 [17.9\%] PPHN, 11 [19.6\%] PDA, and 33 [58.9\%] having no congenital abnormalities at all.

\begin{tabular}{|cc|}
\hline Characteristics & $\mathbf{N}[\%]$ /Median [IQR ] \\
Delivery Methods & - \\
Normal vaginal delivery & $346[36.8]$ \\
Forceps delivery & $111[11.8]$ \\
LSCS & $484[51.4]$ \\
Age during screening [hours] & $633[67.3]$ \\
$<24$ & $308[32.7]$ \\
$\geq 24$ & $8.0[6,24]$ \\
Median [ IQR] & - \\
Age of gestations [weeks] & $284[30.2]$ \\
$37-38$ & $414[44.0]$ \\
$39-40$ & $243[25.8]$ \\
$41-44$ & - \\
Birth weight [kg] & $226[24.0]$ \\
$1400-2700$ & $228[24.2]$ \\
2701-3000 & $331[35.2]$ \\
3001-3500 & $156[16.6]$ \\
3501-4600 & \\
Table 1. Clinical Characteristics and Demographics of the Study \\
Newborns; Darbhanga Medical College \& Hospital, Laheriasarai, \\
\multicolumn{2}{c}{ Bihar, June 2017 } \\
\hline
\end{tabular}

At the time of initial screening, among 941 study newborns, 123 [13.1\%] and 70[7.4\%] of them have either foot and right hand $\mathrm{SpO}_{2}$ level $<95 \%$ respectively. The average either foot and right arm $\mathrm{SpO}_{2}$ level of the study newborns were 95.8\% [SD 2.3] and 96.0\% [SD 2.2] respectively. Nearly, 142 [15.1\%] study newborns had either foot and right arm $\mathrm{SpO}_{2}$ level $<95 \%$ and either foot to right arm $\mathrm{SpO}_{2}$ level variance of $>3 \%$. Repeated 2 nd or $3 \mathrm{rd} \mathrm{SpO}_{2}$ level measurement were done for those 142 study newborns and only 56 [39.4\%] of them having screening test positive. The echocardiographic examinations were performed for those 56 newborns having $\mathrm{SpO}_{2}$ screening test positive. The echocardiographic outcomes were 2[3.6\%] ASD, 10 [17.9\%]
PPHN, 11 [19.6\%] PDA and 33 [58.9\%] having no abnormalities at all.

\begin{tabular}{|cc|}
\hline Characteristics & Values \\
First foot $\mathrm{SpO}_{2}$ & - \\
$<95 \%$ & $123[13.1]$ \\
$\geq 95 \%$ & $818[86.9]$ \\
Mean $\pm \mathrm{SD}$ & $95.8 \pm 2.3 \%$ \\
Minimum value & $80 \%$ \\
Maximum value & $100 \%$ \\
First right arm SpO & - \\
$<95 \%$ & $70[7.4]$ \\
$\geq 95 \%$ & $871[92.6]$ \\
Mean $\pm \mathrm{SD}$ & $96.0 \pm 2.2 \%$ \\
Minimum value & $81 \%$ \\
Maximum value & $100 \%$ \\
2nd and 3rd foot SpO & - \\
$<95 \%$ & $56[39.4]$ \\
$\geq 95 \%$ & $86[60.6]$ \\
Requirement of echocardiographic & - \\
screening- & $56[39.4]$ \\
Yes needed & $86[60.6]$ \\
No need & \\
Table 2. Pulse Oximetry Measurement Characteristics of the Study \\
Newborns; Darbhanga Medical College \& Hospital, Laheriasarai, \\
\multicolumn{2}{c}{ Bihar; June 2017 } \\
\hline
\end{tabular}

\section{Epidemiology of Cyanotic CHDs}

Currently, about 1.35 million babies are born with CHD globally every year. Cyanotic CHD is one of the very common birth defects in general populations and is major cause of death in infancy in united states and other developed nations. ${ }^{8,9}$ It covers for $6 \%-10 \%$ of all infant's deaths and about $30 \%-50 \%$ of all deaths from congenital heart malformations. ${ }^{10}$ Most of these premature deaths, particularly occurring in $1^{\text {st }} 2$ weeks of life and are principally due to ductus dependent CHD. Reported birth prevalence of CHD estimates about 8 per 1000 live births.

\section{Risk Factors Causing Increased Prevalence of Cyanotic CHD}

Increased maternal age, Illness at the time of pregnancy like diabetes mellitus, severe infections and Phenylketonuria, high exposure of drugs during pregnancy like anticonvulsants, corticosteroids, alcohols and organic solvents like DDT and other chemicals. ${ }^{11}$ CCHD generally encompasses critical cyanotic congenital heart diseases and left sided obstructive lesions in which cyanosis may or may not be a major clinical presentation.

\begin{tabular}{|cc|}
\hline Lesions & $\begin{array}{c}\text { National Prevalence of All } \\
\text { Cases/1000 Live Births }\end{array}$ \\
Tricuspid atresia & 0.08 \\
Total anomalous pulmonary venous & 0.09 \\
connections [TAPVC] & 0.11 \\
Univentricular heart & 0.16 \\
Double outlet right ventricle & 0.22 \\
Hypoplastic right heart & 0.32 \\
TGA & 0.42 \\
TOF & $\mathbf{1 . 7 5}$ \\
Total & Table 1. Estimates of Birth Prevalence of Critical \\
Cyanotic Congenital Heart Disease [CHD]
\end{tabular}

\begin{tabular}{|cc|}
\hline Lesions & National Mean of all Cases/1000 Live Births \\
Interrupted aortic arch & 0.07 \\
Stenotic aortic valve & 0.40 \\
Aortic coarctation & 0.41 \\
Hypoplastic left heart & 0.27 \\
Total & 1.15 \\
Table 2. Estimates of Birth Prevalence of Left Sided Obstructive Lesions \\
\hline
\end{tabular}




\section{DISCUSSION}

Pulse oximetry [oxygen-hemoglobin saturations; $\mathrm{SpO}_{2}$ ] should be assessed in children with respiratory or cardiac compromise and also in children with underlying abnormalities of oxygenation. Healthy children have $\mathrm{SpO}_{2}$ $>95 \%$. We have considered evaluations for cardiac causes in children with $\mathrm{SpO}_{2}<93-95 \%$. For children with underlying abnormalities, the child's baseline $\mathrm{SpO}_{2}$ should be assessed and alterations from that baseline should be investigated further. Pulse oximetry can detect cyanotic congenital heart disease with a sensitivity of $76.5 \%$ [95\% CI $67.7 \%$ to $83.5 \%$ ] and a specificity of $99.9 \%$ [99.7\% to $99.9 \%]$. The false positive rare for detection of cyanotic congenital heart disease is lower when pulse oximetry is done after 24 hours from birth.

Pulse oximetry is an excellent non-invasive tool for monitoring $\mathrm{SpO}_{2}$ and should be the part of the standard neonatal care as well as useful screening tool for detection of cyanotic congenital heart disease. Pulse oximetry screening should include measurement of oxygen saturations in both pre-ductal [right hand] and post-ductal [foot] locations. Thus, POS has established itself as a useful screening tool for CHDs particularly for critical cyanotic CHDs.12-15 As per the recent recommendations from American Academy of pediatrics [AAP], all newborns should undergo pulse oximetry screening. ${ }^{14}$ POS should be done after 24 hours of age or shortly before discharge if the neonates is less than 24 hours of age. Waiting until 24 hours of life decreases false positive results due to respiratory ailments. $\mathrm{SpO}_{2}$ less than $95 \%$ represent hypoxemia and at this cut-off pulse oximetry reaches high specificity of more than $99 \%$ and a sensitivity of $75 \%$ for detecting cyanotic CHD.

At the time of initial screening, among 941 study newborns, 123 [13.1\%] and 70 [7.4\%] of them have foot and right hand $\mathrm{SpO}_{2}$ level $<95 \%$ respectively. The mean foot and right arm $\mathrm{SpO}_{2}$ level of the study newborns were 95.8\% [SD 2.3] and 96.0\% [SD 2. 2] respectively. 142 [15.1\%] study newborns have either initial foot or right arm $\mathrm{SpO}_{2}$ level $<95 \%$ and foot to right arm $\mathrm{SpO}_{2}$ level difference of $>3 \%$. Repeated second or third $\mathrm{SpO}_{2}$ measurement were done for those 142 study newborns and only 56 [39.4\%] of them having positive test. Echocardiography examinations have been done for those 56 newborns having positive $\mathrm{SpO}_{2}$ screening test. The echocardiographic findings were 2 [3.6\%] ASD, 10 [17.9\%] PPHN, 11 [19.6\%] PDA, and 33 [58.9\%] having no abnormalities at all.

\section{Benefits of Early Diagnosis of CCHD}

There is significant ratio of neonates demanding cardiac surgical intervention have more importance over the years for contrary neurodevelopmental outcomes of these infants ${ }^{16,17}$. Although, primary diagnosis and treatment of CCHD will reduce neurological brain injury by giving a more stable perioperative care. Early detection of severely complicated forms of critical CCHD helps to save the life by reducing the mortality.

\section{Prenatal Diagnosis}

Studies held in the department of pediatrics, SNCU, Darbhanga medical college \& hospital, Laheriasarai,
Darbhanga, Bihar had shown that about 30\%-50\% of newborns with critical cyanotic CHD are sent home after birth without diagnosis. Therefore, anti-natal diagnosis is essential. Prenatal diagnosis of various cardiac anomalies usually occurs through ultra-sonographic screening test by 18-20 weeks of gestation. The prenatal diagnosis fluctuates from $8 \%$ to $48 \%$ but is on an average $25 \%-30 \%$ in several works. In some study in western US only $28 \%$ CCHD cases are diagnosed, in United Kingdom 35\% and in United States $39 \% .{ }^{18}$ Two essential factors affecting prenatal diagnosis of critical Cyanotic CHD are the type of diseases and types of medical training accomplishing the screening ultrasonographic test. Total anomalous pulmonary venous connection $(0 \%)$, transposition of great vessels $(19 \%)$ and left sided obstructive disorders $(23 \%)$ had the minimum prenatal diagnosis rates. The Heterotaxy $82 \%$, Univentricular diseases (64\%) and Hypoplastic left heart syndrome (61\%) had the highest detection rates. The existence of several cardiac disorders leads to more focussed and meticulous assessment, the prenatal diagnosis rate of critical CCHD is greater in foetuses with multiple congenital cardiac disorders and is lesser in foetuses with inaccessible CCHD. With greater efforts and higher attention to enhance prenatal diagnosis, Australia and Czech Republic were capable to attain prenatal diagnosis rate of $53 \%$ and $80 \%$ respectively. ${ }^{18}$

\section{Postnatal Diagnosis}

The limitations of clinical examinations of cyanotic CHD comprise reduced specificity of cardiac murmurs in neonates, absence of any cardiac findings including murmur in nearly $50 \%$ of all infants with CCHD and limited physicians having experience in differentiating innocent from pathological murmurs. Also, many studies have obviously revealed that the visual assessment of cyanosis is suboptimal.11,10 Multiple factors other than oxygenation can also impact detection including skin colour, thickness of skin, perfusion, haemoglobin level and environmental elements resembling ambient light.

\section{Current Guidelines of CCHDs}

The United States Health and Human Services Secretary's Advisory Committees on Heritable Disorders in Newborn and Children formed a work group in collaborative with the AAP, AHA and the American College of Cardiology Foundation reviewed the indications of pulse oximetry screening for primary diagnosis of critical Cyanotic CHD. The working association were printed their endorsements in 2011 that were successively recommended by AAP, AHA and other organisations. ${ }^{1}$ The guiding principles recommended that all neonates should receive pulse oximetry screening test soon after birth at 24 hours or before discharge from hospital. The screening test should be accomplished by measuring partial pressure of oxygen saturations in the right hand [pre-ductal saturation] and one foot [post-ductal saturation] either synchronously or instantly one after the other. An oxygen saturation of $\geq 95 \%$ in the right hand or either foot and $\leq 3 \%$ difference between right hand and foot is reflected as negative result and further no assessments needed before discharge. ${ }^{1}$

A screening test is reflected as positive or negative if oxygen saturations is lower than $95 \%$ in both extremities 
after three or more consecutive measurements [conducted one hour apart] or if difference of oxygen saturations between pre-ductal and post-ductal saturations is more than $3 \%$ after three consecutive measurements. Infants who were not undergone primary screening test should have diagnostic echocardiogram and assessment by a physician or pediatric cardiologists. ${ }^{1}$ Infants with positive screening test will not always have critical CCHD. Infants with additional illness associated with low $\mathrm{SpO}_{2}$ like persistent pulmonary hypertension and certain hemoglobinopathy may also have a positive screening in addition to critical CCHD. ${ }^{1}$

\section{Limitations}

The primary limitations of pulse oximetry screening is its reduced sensitivity in many studies. The sensitivity varies from $62 \%$ to $78 \%$. It is essential for health care providers and parents to realize that a simple screening test at birth does not exclude the possibility of critical cyanotic CHD. As considered, numerous false negative results of ductusdependent systemic circulations observed like aortic coarctations, severe stenotic aortic valve diseases. A vigorous follow up programmes to know the extent of false-negative results in cases of global screening may permit chances to advance the screening algorithm. Thus, with greater awareness, automated interpretations of data and efficient diagnosis we can detect and manage these problems.

\section{CONCLUSIONS}

Pulse oximetry screening test for primary diagnosis of critical cyanotic CHD is an easier, low cost and noninvasive technique which covers the essential principles for supplementation to global neonatal screening strategies. With higher recognition and approval, the initial screening test can significantly decrease morbidity and mortality related to critical CCHD which is noticeable in poor resource backgrounds where many births occur without prenatal detection. This study shows low sensitivity of pulse oximetry test for critical CCHD nearly $<50 \%$.

The pre-ductal and post-ductal $\mathrm{SpO}_{2}$ levels of study newborns were nearly the same $96.0 \%$ and $95.8 \%$ respectively. Though, the average $\mathrm{SpO}_{2}$ values of study newborn were lower than $97.4 \%$ as compared to average $\mathrm{SpO}_{2}$ values reported by other studies. ${ }^{19}$

\section{REFERENCES}

[1] Kempter AR, Mahle WT, Martin GR, et al. Strategies for implementing, screening for critical congenital heart disease. Pediatrics 2011;128(5):1259-67.

[2] Tennessee Department of Health. Protocol for critical congenital heart disease (CCHD) screening. 2013. https;//www.tn.gov/content/dam/tn/health/document s/C. Accessed March 23, 2018.

[3] Oster ME, Aucott SW, Glidewell J, et al. Lessons learned from newborn screening for critical congenital heart defects. Pediatrics 2016;137(5):e20154573.
[4] Abouk R, Grosse SD, Ailes EC, et al. Association of US state implementation of newborn screening policies for critical congenital heart disease with early infant cardiac deaths. JAMA 2017;318(21):2111-8.

[5] Rentmeester ST, Pringle J, Hogue CR. An evaluation of the addition of critical congenital heart defect screening in Georgia newborn screening procedures. Matern Child Health J 2017;21(11):2086-91.

[6] Centres for Disease Control and Prevention (CDC). Assessment of current practices and feasibility of routine screening for critical congenital Heart Defects - Georgia, 2012. MMWR Morb Mortal Wkly Rep 2013;62(15):28891.

[7] Nuntnarumit P, Thanomsingh P, Limrungsikul A, et al. Pulse oximetry screening for critical congenital heart diseases at two different hospitals settings in Thailand. J Perinatol 2018;38(2):181-4.

[8] Wilson JM, Jungner YG. Principles and practice of mass screening for disease. Bol Oficiana Sanit Panum 1968;65(4):281-393.

[9] Botto LD, Correa A, Erickson JD. Racial and temporal variations in the prevalence of heart defects. Pediatrics 2001;107(3):E32.

[10] O'Donnell CP, Kamlin CO, Devis PG, et al. Clinical assessment of infant colour at delivery. Arch Dis Child Fetal Neonatal Ed 2007;92(6):F465-7.

[11] Gardiner HM, Kovacevic A, Van Der Heijden LB, et al. Prenatal screening for major congenital heart disease: assessing performance by combining national cardiac audit with maternity data. Heart 2014;100(5):375-82.

[12] Ewer AK, Middletonn LJ, furmston AT, et al. Pulse oximetry screening for congenital heart defects in newborn infants (PulseOx): a test accuracy study. Lancet 2011;378(9793):785-94.

[13] Ewer AK. Pulse oximetry screening for critical congenital heart defects in newborn infants: should it be routine? Arch Dis Child Fetal Neonatal 2014;99(1):F93-5.

[14] Thangaratinam S, Brown K, Zamora J, et al. Pulse oximetry screening for critical congenital heart defects in asymptomatics newborn babies: a systemic review and meta-analysis. Lancet 2012;379(9835):2459-64.

[15] Mahle WT, Martin GR, Beekman RH 3rd, et al. Section on Cardiology and Cardiac Surgery Executive Committee. Endorsement of health and human service recommendation for pulse oximetry screening for critical congenital heart disease. Pediatrics 2012;129(1):190-2.

[16] Gaynor JW, Stopp C, Wypij D, et al. Neurodevelopmental outcomes after cardiac surgery in infancy. Pediatrics 2015;135(5):816-25.

[17] Goldberg CS, Lu M, Sleeper LA, et al. Factors associated with neurodevelopment for children with single ventricle lesions. Pediatric Heart Network Investigators. J Pediatr 2014;165(3): e490-6.e8.

[18] Brown KL, Sullivan ID. Prenatal detection for major congenital heart disease: a key process measure for congenital heart networks. Heart 2014;100(5):359-60.

[19] Bargava R, Mathur M, Patodia J. Oxygen saturation trends in normal healthy term newborns: normal vaginal delivery vs. elective caesarian section. J Perinatal Med 2018;46(2):191-5. 